\title{
Mediating Role of Computer Experience in the Association between MOOC-efficacy and Meaningful Learning
}

Norliza Ghazali, Mohamad Sahari Nordin

To Link this Article: http://dx.doi.org/10.6007/IJARBSS/v11-i12/11903

DOI:10.6007/IJARBSS/v11-i12/11903

Received: 02 October 2021, Revised: 04 November 2021, Accepted: 25 November 2021

Published Online: 11 December 2021

In-Text Citation: (Ghazali \& Nordin, 2021)

To Cite this Article: Ghazali, N., \& Nordin, M. S. (2021). Mediating Role of Computer Experience in the Association between MOOC-efficacy and Meaningful Learning. International Journal of Academic Research in Business and Social Sciences, 11(12), 1759-1770.

Copyright: @ 2021 The Author(s)

Published by Human Resource Management Academic Research Society (www.hrmars.com)

This article is published under the Creative Commons Attribution (CC BY 4.0) license. Anyone may reproduce, distribute, translate and create derivative works of this article (for both commercial and non0-commercial purposes), subject to full attribution to the original publication and authors. The full terms of this license may be seen at: http://creativecommons.org/licences/by/4.0/legalcode

Vol. 11, No. 12, 2021, Pg. $1759-1770$

Full Terms \& Conditions of access and use can be found at http://hrmars.com/index.php/pages/detail/publication-ethics 


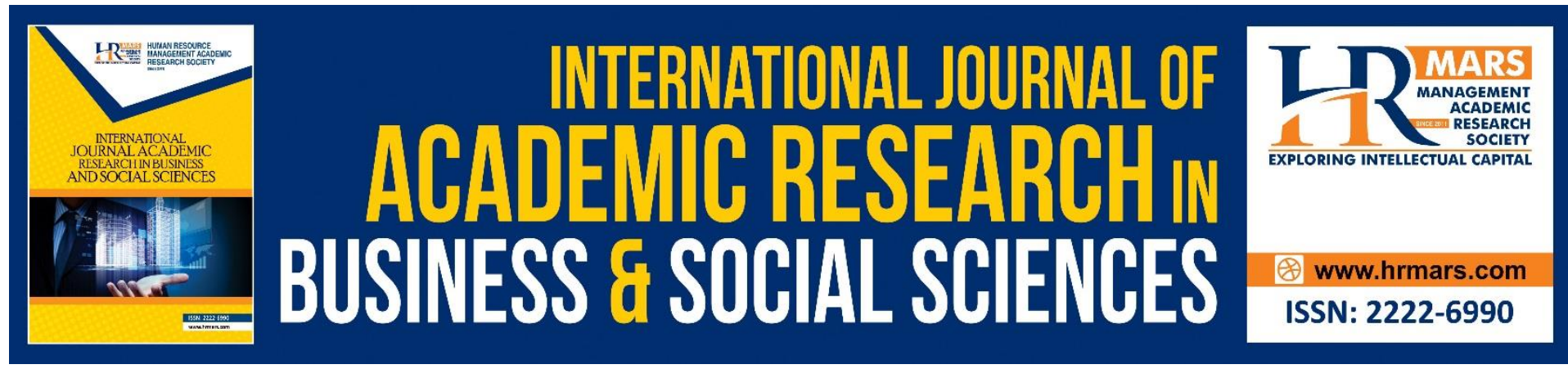

\title{
Mediating Role of Computer Experience in the Association between MOOC-efficacy and Meaningful Learning
}

\author{
Norliza Ghazali ${ }^{1}$, Mohamad Sahari Nordin² \\ ${ }^{1}$ Faculty of Educational Studies, Universiti Putra Malaysia, 43400 Serdang Selangor, \\ Malaysia, ${ }^{2}$ Kulliyyah of Education, International Islamic University Malaysia, P.O. Box 10, \\ 50728 Kuala Lumpur, Malaysia \\ Email: alezg@upm.edu.my,msahari@iium.edu.my
}

\begin{abstract}
This study examines three critical constructs in twenty-first-century e-education-MOOCefficacy, meaningful learning, and computing experience-among undergraduate students at selected public universities in Malaysia. Its primary purpose is to investigate the mediating function of computer experience in the link between MOOC-efficacy and meaningful learning. This study defines MOOC-efficacy based on four aspects (information searching, making queries, MOOC learning, and MOOC usability). Meanwhile, meaningful learning is conceptualised in five dimensions (i.e.cooperative learning, active learning, authentic learning, constructive learning, and intentional learning). This study incorporated a crosssectional survey design. The data were acquired using a 52-item questionnaire whose reliability indices for the dimensions ranged from 0.822 to 0.890 . The study's population comprises university students with prior experience using MOOCs and volunteered to participate in the study. Simple random selection was used to get a sample of 603 students. The Structural Equation Modeling (SEM) test of bootstrapping for mediation was used for data analysis. The findings suggest no evidence of a mediation impact of computer experience on MOOC-efficacy and meaningful learning. The findings add to our understanding of how an open online ecosystem function. This study provides insights that could be used to meet the requirements and preferences of learners. MOOC-efficacy interventions are critical for motivating students to engage in meaningful learning on the e-learning platform.
\end{abstract}

Keywords: Computer Experience, Mediating Role, Massive Open Online Course (MOOC), MOOC-Efficacy, Meaningful Learning.

\section{Introduction}

In response to the growing use of e-learning in advanced higher education, the creation of Massive Open Online Courses (MOOCs), a learning platform quickly garnering international attention, was inevitable. Compared to other forms of online education, MOOCs are a relatively new phenomenon that encourages the use of internet-based courses and the exploitation of open educational resources (Dunn \& Kennedy, 2019; Gómez-Galán et al., 2020). It has been suggested that MOOCs could be a new way to improve teaching and 
learning in the 21st-century educational context (Ghazali et al., 2020). They have gained widespread acceptance due to their adaptability to various learning situations, their flexibility in student learning, and their accessibility in the contexts of pursuing education and professional development (Ministry of Education Malaysia, 2015). Due to the MOOC initiative's recent inception and exploratory nature in Malaysia, it is evident that there are numerous concerns to address and gaps to overcome. Currently, gaps in existing MOOC projects indicate a considerable possibility for development (Adzhar et al., 2017; Ghazali et al., 2021).

Students' self-efficacy beliefs are important in determining the MOOC model's effectiveness as an online learning approach (Branson, 2017; Pilli \& Admiraal, 2017; Wang \& Baker, 2015). Self-efficacy is defined as students' perceptions of their ability to complete specific tasks successfully (Bandura, 2000; Rodriguez \& Armellini, 2017). As a measure of students' effort, motivation, involvement, and performance, self-efficacy is a critical construct that could help increase the understanding of MOOC completion. Earlier research indicates that self-efficacy is a critical factor in shaping students' behaviour, performance, achievement, and learning (Abdullah et al., 2015; Bandura, 2000). The current study examines the effect of MOOC efficacy on meaningful learning. Any pedagogical use of technology, such as MOOCs, should deliver relevant learning experiences for students (Jonassen et al., 2003; Howland et al., 2013).

Past studies have examined the association between students' self-efficacy and performance using different demographic variables (e.g. Bandura, 1986; Achterkamp, Hermens \& Vollenbroek-Hutten, 2015; McKay et al., 2014). While there is wide research on the various demographic factors on the association between self-efficacy and performance, research findings are still inconclusive. A wide body of literature shows that equivalent knowledge or experience in the performance domain influences the association between individuals' self-efficacy and performance. Evidence indicates the mediation effects of computer self-efficacy on variables like computer anxiety and intention to use computers (Kevin, Richard \& Douglas, 2007). On the other hand, computer self-efficacy has been found to fully mediate the relationship between attitudes and levels of ICT use (AI Dafaei et al., 2013). The literature and research regarding computer experience as a mediator between self-efficacy and performance are limited, especially in the context of MOOCs (Littlejohn et al., 2016). Pili and Admiraal (2017) suggested examining the difference between experienced and novice students concerning the learning behaviour they exhibit in a MOOC. In this light, students' experience could be examined in terms of computer experience or MOOC experience.

Therefore, this study attempts to test whether or not students' computer experience mediates the relationship between students' MOOC-efficacy and meaningful learning. Establishing computer experience as a mediator will undoubtedly add to the existing body of knowledge. Thus, this has led to the formulation of the following research question: Does computer experience mediate the relationship between students' MOOC-efficacy and meaningful learning. This research question was addressed based on this hypothesis: 'Computer experience mediates the association between students' MOOC-efficacy and meaningful learning'.

\section{Literature Review}

The purpose of this study is to explain the study's central theoretical component, MOOC-efficacy, and to tie it to meaningful learning through the use of computer experience 
as a mediating factor. MOOC-efficacy refers to an expanded version of the Self-efficacy in Internet-Based Learning Environments scale, or SIBLE (Chen, 2014), and the paradigm for meaningful learning used in this study (Howland et al., 2013). Students' MOOC efficacy relates to their capacities and perceptions regarding their ability to complete certain learning objectives in MOOCs. In the meantime, meaningful learning engages students' intellectual curiosity and engages them in dynamic instructional activities.

The SIBLE scale (Chen, 2014) was adopted to assess students' MOOC efficacy. MOOC efficacy in this study was conceptualised into four critical dimensions: (i) information searching, (ii) making queries, (iii) MOOC learning, and iv) MOOC usability. The SIBLE scale is well-suited for capturing the enigmatic idea of perceived self-efficacy since it has strong psychometric qualities and examines a broad range of competencies necessary for a virtual learning environment (Chen, 2014; Cheng \& Tsai, 2011; Ching et al., 2014). The SIBLE scale was created by combining two survey instruments: the online academic help-seeking (OAHS) behaviour survey and the self-efficacy for web-based learning (WLSE) survey.

The empirical evidence on the influence of self-efficacy on students' behaviour, performance and accomplishment suggests that children with a strong belief in their abilities will succeed in school (Abdullah et al., 2015; Bandura, 2000; Rodriguez \& Armellini, 2017; Zimmerman, 2000). Thus, this current study investigates and examines the relationship between MOOC efficacy and meaningful learning. In accordance with past research recommendations, this study will investigate whether major disparities in students' MOOC capacities will affect their ability to self-regulate their learning, making it more relevant (Ghazali et al., 2020; Hood et al., 2015; Koh, 2017; Pilli \& Admiraal, 2017).

The meaningful learning framework developed by Howland et al. (2013), which comprises five components, including (i) cooperative learning, (ii) active learning, (iii) authentic learning, (iv) constructive learning, and (v) intentional learning, was used in this study. Meaningful learning entails comprehending how the information acquired fits into a larger picture. Unlike rote learning, which enforces memory of knowledge through repetition of the same material, meaningful learning entails a combination of multiple teaching and learning activities that allow students to gain knowledge, reflect on their experiences, and explain the information they learned during learning activities (Ghazali \& Nordin, 2019; Sailin \& Mahmor, 2018).

Experience refers to one's practical contact with the observation of events. Experience enables a person to acquire knowledge and skills, especially in a particular field or profession. The longer one observes or interacts with an event, the more skills and knowledge they will gain through the experience (Bandura, 1986). Past research suggested that computer selfefficacy and computer experience mediate the relationship between an individual's selfefficacy and performance (Igbaria \& livari, 1995). While a large amount of the literature has concentrated on computer self-efficacy, very little research has focused on examining computer experience as a mediating factor in the context of internet-based self-efficacy and performance (Littlejohn et al., 2016).

Studies have presented evidence of the mediation effects of computer self-efficacy on variables like computer anxiety and the intention to use computers (Pauli, Gilson \& May 2007). On the other hand, computer self-efficacy has been found to fully mediate the relationship between attitudes and levels of ICT use (AI Dafaei et al., 2013). Computer experience was found to have a strong positive direct effect on computer self-efficacy (Jerry \& Emrah, 2008). Previous literature has revealed that equivalent knowledge or experience in the performance domain influenced the association between an individual's self-efficacy and performance (e.g. Achterkamp, Hermens \& Vollenbroek-Hutten, 2015; Bouffard-Bouchard, 
1990) while some studies did not find any influence (e.g. LaForge-MacKenzie \& Sullivan, 2014; Klassen \& Chiu, 2010). A recent study by Pili and Admiraal (2017) suggested examining the difference between experienced and novice students exhibiting their learning behaviour in a MOOC. Thus, this study examines whether students' computer experience mediates the association between their MOOC-efficacy and meaningful learning. The conceptual framework of the research is shown in Figure 1.

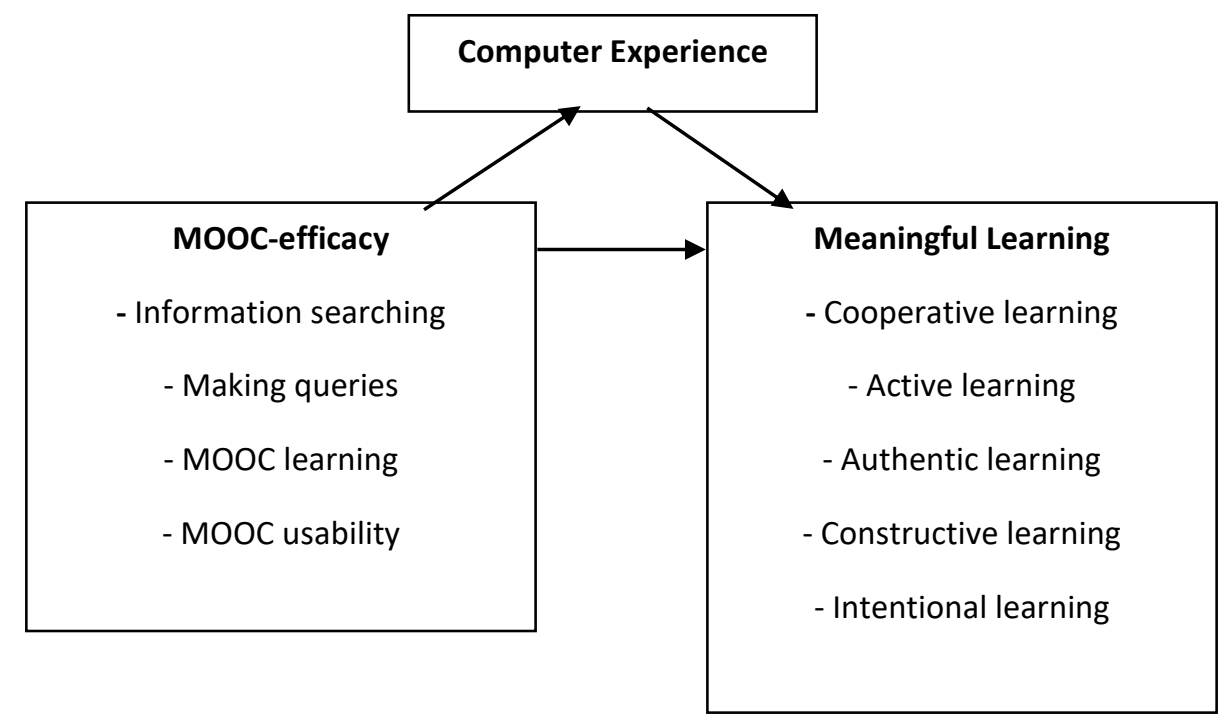

Figure 1 Conceptual framework of the research

\section{Materials and Methods}

This study used the cross-sectional survey design, which is strictly quantitative in nature. The information was gathered through a standardized survey questionnaire.

\section{Measures}

The following methods and techniques were adopted from The Standards for Educational and Psychological Testing to produce items focusing on MOOC-efficacy and meaningful learning (American Psychological Association, 2014.). The content validity ratio (CVR) was used to assess the validity of both scales' content in terms of validity. A total of 52 questions were categorized into four dimensions to represent MOOC-efficacy, and five dimensions were set to measure students' meaningful learning. The items were distributed evenly across the four dimensions. The reliability of the measurement instrument is acceptable, with values ranging from 0.822 to 0.890 for MOOC-efficacy and 0.838 to 0.885 for meaningful learning (Ghazali et al., 2020).

\section{Respondents}

The study's respondents consist of students from three public universities in Malaysia (namely, Universiti Putra Malaysia (UPM), Universiti Sains Islam Malaysia (USIM), and Universiti Teknologi Mara (UTM)). The study population comprises university students with prior experience with MOOCs and who voluntarily participated in the study $(\mathrm{N}=1,524)$. The population was chosen in this manner so that the study could have a clearly defined sampling frame, which would allow for simple random sampling to be used.

There were four parameters evaluated when determining the sample size for this study to maximise the precision in parameter estimation: the population size, the allowable 
margin of error, the complexity of the hypothesised model, and the level of confidence that was required for the study. The selection of these elements was based on the number of latent variables, indicators, and path linkages included in the model at the time of selection (Kline, 2011). Previous scientific literature offers some principles for estimating the minimal sample size required to provide sufficient statistical power in data analysis. The present study accepted a 5 per cent margin of error and a 95 per cent confidence level for its findings. As a result, based on the size of the target population for this study $(\mathrm{N}=1,524)$, it was determined that the sample size should be 95 per cent $5=306$ according to Krejcie and Morgan's (1970) recommendations for determining minimum sample size should be used.

Following that, the researcher picked 50 per cent of the students in the sample frame ( $n=1,524$ students) as respondents using a random number generation procedure in SPSS to acquire sufficient data to make up for any potential missing respondents from the sampling frame. A total of 762 questionnaires were distributed to respondents. The researcher briefed the respondents at the start of data collection to clarify the research objective. The respondents were given 15 minutes to complete the questionnaire and were instructed to submit the completed questionnaire as quickly as possible. This approach helps ensure the respondents have sufficient time to respond to the items on the spot, reducing the likelihood of a lost or forgotten questionnaire.

\section{Data Analysis Strategy}

Structural Equation Modeling (SEM) was used to analyse the collected data. It was decided to use the complete SEM method for this investigation. By including variables into a structural model, SEM can estimate chains of direct and indirect causal influences among variables simultaneously, resulting in more accurate estimates (Baleghi-Zadeh et al., 2014; Hair et al., 2010). It enables the researcher to test a series of causal relationships between the independent and dependent variables (Ho, 2006) compared to first-generation methods such as the multiple regression analysis (Byrne, 2013). The ability of SEM to analyse the influence of several and connected variables simultaneously is the most significant characteristic of the technique.

In the context of this study, the bootstrapping method was used to examine the significance of the mediation paths between students' MOOC-efficacy and meaningful learning through computer experience. Specifically, the bias-corrected bootstrap method was applied using a sample of 1,000 bootstrapped cases with $95 \%$ confidence intervals. Bootstrap is the technique recommended to estimate the statistical significance of a construct's mediation effects (Cheung \& Lau, 2008; MacKinnon, 2008). Specifically, the study used a bias-corrected bootstrap technique because it offers greater statistical power and confidence interval precision (Mallinckrodt et al., 2006; Cheung \& Lau, 2008). This study followed the procedure and guidelines presented by Mallinckrodt et al. (2006) and Cheung and Lau (2008) for executing a bootstrap mediation test with AMOS.

\section{Results}

\section{Demographic Information}

Out of the 762 questionnaires distributed, 657 sets were returned, representing an 86.22 per cent response rate. 34 questionnaires were deemed unusable due to the presence of missing data. According to Sekaran and Bougie (2016), a return rate of $75 \%$ is required for a research study to successfully achieve its purpose and objectives. In this regard, the return rate of 81.76 per cent $(n=623)$ obtained in this study is significantly higher than expected. 
The sample rate is also deemed appropriate for SEM analysis in educational research, where Kline (2011) recommended sample size of 200. Moreover, Hair et al (2010) advised a minimum sample size of 100 to 150 to ensure a consistent maximum likelihood estimation. Following the discovery of the outliers, the data set was reduced to a final sample of 603 individuals for further analysis.

\section{Mediation Effect of Computer Experience in the Association between MOOC-efficacy and Meaningful Learning}

After the measurement model was validated, it was transformed into a hypothesised structural model to test the causal effect of MOOC-efficacy on meaningful learning with hypothesised causal paths. Figure 2 depicts the resulting structural model of MOOC-efficacy and meaningful learning and the produced standardised estimates and fit indices. The fit indices indicate an adequate fit: $\mathrm{RMSEA}=0.041, \mathrm{CFI}=0.923$ and $\chi 2 / \mathrm{df}=2.028$. According to Hair et al. (2010), a hypothesised conceptual model with an RMSEA value of $<0.08$, a CFI value of $\geq 0.90$ and a normed chi-square value of $2.0 \leq \chi 2 / \mathrm{df} \leq 5.0$ fulfils the conditions of a valid model. Thus, the MOOC-efficacy-meaningful learning structural model indices are within the acceptable parameters. A good model fit is a requirement for accepting a structural model.

Figure 2 and Table 1 indicate no mediation effect of computer experience was detected between students' MOOC-efficacy and meaningful learning. Hence, the Hypothesis: Computer experience mediates the association between MOOC-efficacy and meaningful learning is not supported. The finding is summarised in Figure 2 and Table 1 below.

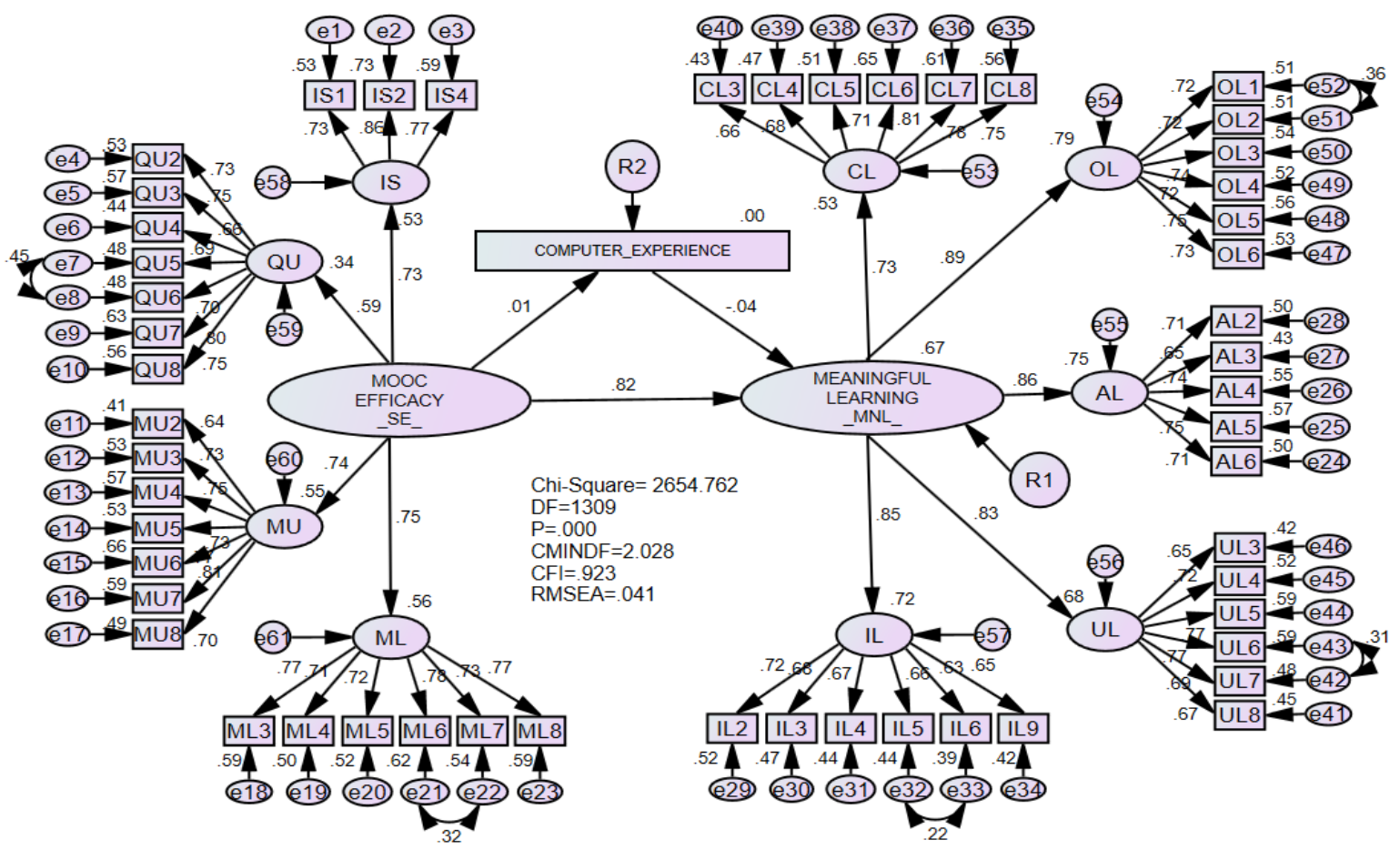

Figure 2 Mediation Effect of Computer Experience on the Association Between MOOC-efficacy and Meaningful Learning 
Table 1. The Summary - Mediation Effect of Computer Experience on the Association between MOOC-efficacy and Meaningful Learning

\begin{tabular}{lcc}
\hline & Indirect Effect & Direct Effect \\
\hline Bootstraping Result & 0.001 & 0.816 \\
Bootstraping P-value & 0.825 & 0.002 \\
Result & Not significant & Significant \\
Type of mediation & \multicolumn{2}{c}{ No mediation effect } \\
\hline
\end{tabular}

\section{Discussion}

The research question sought to verify the role of computer experience as a mediator between MOOC-efficacy and meaningful learning. The mediating effect of computer experience was tested in Hypothesis-Computer experience mediates the association between MOOC-efficacy and meaningful learning. This study's finding shows that computer experience does not mediate the relationship between MOOC-efficacy and meaningful learning. Thus, the hypothesis was not supported. Based on this finding, it can be concluded that computer experience does not interact with the MOOC-efficacy to influence meaningful learning: hence, computer experience is not a mediating variable.

This study's finding aligns with Bandura (2000), which postulates that positive selfefficacy beliefs affect self-directed learning ability leading to successful academic outcomes or performance. Regardless of computer experience, individuals with a high level of selfefficacy are confident in their abilities, self-motivated, able to regulate their learning and work with minimal guidance, persistent in facing difficulties and tend to have high goal achievement. As a result, they are also more engaged in meaningful learning. As computer experience does not mediate the association between students' MOOC-efficacy and meaningful learning, the hypothesis is not supported by the data.

Students with high MOOC efficacy are confident and capable of self-directed learning. When faced with learning challenges on their respective MOOCs, they tend to increase their effort, thus leading to more meaningful learning (Bandura, 2000). Additionally, computer experience has no mediating effects on the relationship between the constructs (students' MOOC-efficacy and meaningful learning). The findings support the existing perspective that positive self-efficacy beliefs influence self-directed learning ability, increase students' effort to face challenges and pave the way to successful performance in MOOCs, helping them engage in more meaningful learning.

\section{Limitations and Recommendations}

This study is not without its limitations. One of the study's limitations is that it relied on only one source of data, specifically the self-reported students' MOOC-efficacy and meaningful learning questionnaire. This limitation hindered the researchers' ability to obtain an accurate data set image. There are a variety of factors contributing to this. First and foremost, respondents of self-reported questionnaires may not report their real responses. In this sense, they may lack the self-awareness necessary to answer the questionnaire items correctly or not grasp the significance of this research project. As a result, the study could not guarantee the high accuracy of the information gathered. Hence, additional data were obtained through document analysis and other quantitative or qualitative methods such as interviews and observations. Another disadvantage of this study is the low response rate and lack of information. The response rate for the study was completely out of the researcher's control. The information provided by the students reflected their ideas at the time the survey 
was administered, which was when the data was collected. Their beliefs may change throughout time as a result of their experiences. Furthermore, the researcher had no control over other factors influencing students' responses, such as their emotional state and mental stability while answering the questionnaire. For instance, students who answered the questionnaire might do so in a hurry as they have other personal matters they need to attend to.

All respondents in this study are undergraduate students from Malaysian public higher education institutions. Therefore, further research should include graduate students in their samples rather than restricting themselves to undergraduates. Similarly, the target populations might be enlarged to include a greater number of institutions of higher learning to ensure that the findings are generalisable. Future research should also consider the diverse student and lecturer populations in Malaysia's private learning institutions. The findings of large-scale investigations should generate more inclusive and far-reaching conclusions. According to scholars, self-efficacy is a complex, multidimensional, domain- and culturespecific construct (e.g. Wang \& Baker, 2015). Self-efficacy is most effectively measured concerning certain abilities. This study altered the SIBLE (Chen, 2014) dimensions to create a psychometrically sound instrument to assess MOOC efficacy among students. The dimensions were constrained to SIBLE's specifications (Chen, 2014). The data indicate that the four MOOC-efficacy variables had a strong beneficial effect on students' meaningful learning. The findings of this study open the door for future research to examine other demographic aspects as mediating factors, such as digital competence, MOOC facility, MOOC interaction, or time management in MOOCs. These other demographic factors may provide further information on the antecedents of meaningful learning.

\section{Conclusion}

MOOCs present a new online medium for course delivery and learning in 21st-century education. It can be used to provide high-quality learning content and interactive learning tools to a large number of students effortlessly. In the context of this research, computer experience was not found to be a significant mediator of the link between MOOC-efficacy and meaningful learning. The finding also includes the fact that no mediation effect was detected between students' MOOC-efficacy and meaningful learning through students' computer experience. Students with high MOOC efficacy are more confident and capable of selfdirected learning. Furthermore, when faced with challenges in their respective MOOCs, they tend to increase their effort, thus leading to more meaningful learning.

\section{References}

Abdullah, Z., Ramlan, M. F. H., Sabran, M. S., \& Alsagoff, S. A. S. (2015). Towards a university branding: The effect of self-efficacy on student development in a major higher education institution. Jurnal Personalia Pelajar, 17, 49-61.

Achterkamp, R., Hermens, H., \& Vollenbroek-Hutten, M. (2015). The influence of success experience on self-efficacy when providing feedback through technology. Computers in Human Behavior. 52, 419-423.

Adzhar, H., Khalid, F., \& Karim, A. A. (2017). Penggunaan massive open online course (MOOC) sebagai kaedah pembelajaran baharu. In R. Mohamed Rosly, N. A. Razali, \& N. A. Jamilluddin (Eds.), Pembelajaran abad ke-21: Trend integrasi teknologi (pp. 179-188). Fakulti Pendidikan UKM. 
American Psychological Association (APA). (2014). The standards for educational and psychological testing. American Educational Research Association.

Baleghi-Zadeh, S., Ayub, A. F. M., Mahmud, R., \& Daud, S. M. (2014). Learning management system utilisation among Malaysian higher education students: A confirmatory factor analysis. Journal of Education \& Human Development, 3(1), 369-386. https://doi.org/10.7575/aiac.ijels.v.2n.1p.29

Bandura, A. (2000). Self-efficacy. In A. Kazdin (Ed.), Encyclopedia of Psychology (pp. 212-213). Oxford University Press.

Bandura, A. (1986). Social foundations of thought and action. Englewood Cliffs, NJ: Prentice Hall.

Bouffard-Bouchard, T. (1990). Influence of self-efficacy on performance in a cognitive task. Journal of Social Psychology, 130(3), 353-363. https://doi.org/10.1080/00224545.1990.9924591

Branson, K. J. (2017). Academic Self-Efficacy and Massive Open Online Course (MOOC) Completion Rates: Do Academic Self-Efficacy and Adult Learner Characteristics Influence MOOC Outcomes? [PhD Thesis]. San Diego State University.

Byrne, B. M. (2013). Structural equation modelling with Mplus: Basic concepts, applications, and programming. New York: Routledge.

Chen, Y. L. (2014). A study on student self-efficacy and technology acceptance model within an online task-based learning environment. Journal of Computers, 9(1), 34-43. https://doi.org/10.4304/jcp.9.1.34-43

Cheng, K. H., \& Tsai, C.-C. (2011). An investigation of Taiwan University students' perceptions of online academic help-seeking, and their web-based learning self-efficacy. The Internet and Higher Education, 14(3), 150-157.

https://doi.org/10.1016/j.iheduc.2011.04.002

Cheung, G. W., \& Lau, R. S. (2008). Testing mediation and suppression effects of latent variables: Bootstrapping with structural equation models. Organizational Research Methods, 11(2), 296-325. http://dx.doi.org/10.1177/1094428107300343

Ching, G. S., Lin, M.-C., Wang, W.-L., \& Tchong, W.-L. (2014). Self-efficacy and online helpseeking tendencies of EFL learners. International Journal of Learning Technology, 9(4), 374-391. https://doi.org/10.1504/IJLT.2014.067734

Dunn, T. J., \& Kennedy, M. (2019). Technology Enhanced Learning in higher education, motivations, engagement and academic achievement. Computers \& Education, 137, 104-113. https://doi.org/10.1016/j.compedu.2019.04.004

Ghazali, N., Nordin, M. S., Abdullah, A., \& Ayub, M. A. F. (2020). The relationship between students' MOOC-efficacy and meaningful learning. Asian Journal of University Education, 16(3), 89-101.

Ghazali, N., Mustakim, S. S., \& Nordin, M. S. (2021). Assessing the psychometric properties of students' MOOC-efficacy measurement model. Pertanika Journal Social Science \& Humanities, 29 (S1): $215-235$.

Ghazali, N., \& Nordin, M. S. (2019). Measuring Meaningful Learning Experience: Confirmatory Factor Analysis. International Journal of Innovation, Creativity and Change, 9(12), 283296.

Gómez-Galán, J., Lázaro-Pérez, C., Martínez-López, J. Á., \& López-Meneses, E. (2020). Measurement of the MOOC Phenomenon by Pre-Service Teachers: A Descriptive Case Study. Education Sciences, 10(9), 215. https://doi.org/10.3390/educsci10090215 
Hair, J. F., Black, W. C., Babin, B. J., Anderson, R. E., \& Tatham, R. L. (2010). Multivariate data analysis (7th ed.). Pearson Education International.

Ho, R. (2006). Handbook of univariate and multivariate data analysis and interpretation with SPSS. Florida: CRC press.

Howland, J. L., Jonassen, D. H., \& Marra, R. M. (2013). Meaningful Learning with Technology: Pearson New International Edition (4th ed.). Boston, MA: Pearson Higher Ed.

Igbaria, M., \& livari, J. (1995). The effects of self-efficacy on computer usage. Omega, Int. J. Mgmt Sci, 23(6), 587-605. https://doi.org/10.1016/0305-0483(95)00035-6

Jerry, C. M., \& Emrah, O. (2008). The impact of Organizational Culture on Knowledge Workers' Computer Self-Efficacy. In K. O'Sullivan (Ed..), $5^{\text {th }}$ International Conference on Intellectual Capital, Knowledge Management \& Organisational Learning. New York Institute of Technology. New York, USA.

Jonassen, D. H., Howland, J., Moore, J., \& Marra, R. M. (2003). Learning to solve problems with technology: A constructivist perspective. New Jersey: Merrill Prentice Hall.

Kevin, P. P., Richard, L. G., \& Douglas, R. M. (2007). Anxiety and avoidance: The mediating effects of computer self-efficacy on computer anxiety and intention to use computers. Review of Business Information System, 11(1), 57-64.

Klassen, R. M., \& Chiu, M. M. (2010). Effects on teachers' self-efficacy and job satisfaction: teacher gender, years of experience, and job stress. Journal of Educational Psychology, 102(3), 741-756. https://doi.org/10.1037/a0019237

Kline, R. (2011). Principles and practice of structural equation modelling, (2nd ed.). New York: The Guilford Press.

Krejcie, R., \& Morgan, D. (1970). Determining sample size for research activities. Educational and Psychological Measurement, 30, 607-610.

LaForge-MacKenzie, K., \& Sullivan, P. J. (2014). The relationship between self-efficacy and performance within a continuous educational gymnastics routine. International Journal of Sport and Exercise Psychology, 12(3), 206-217.

https://doi.org/10.1080/1612197X.2014.909511

Littlejohn, A., Hood, N., Milligan, C., \& Mustain, P. (2016). Learning in MOOCs: Motivations and self-regulated learning in MOOCs. Internet and Higher Education, 29, 40-48. https://doi.org/10.1016/j.iheduc.2015.12.003

MacKinnon, D. P. (2008). Introduction to statistical mediation analysis. New York, NY: Lawrence Erlbaum Associates.

Mallinckrodt, B., Abraham, W. T., Wei, M., \& Russell, D. W. (2006). Advances in testing the statistical significance of mediation effects. Journal of Counseling Psychology, 53(3), 372-378. https://doi.org/10.1037/0022-0167.53.3.372

McKay, M. T., Dempster, M., \& Byrne, D. G. (2014). An examination of the relationship between self-efficacy and stress in adolescents: the role of gender and selfesteem. Journal of Youth Studies, 17(9), 1131-1151.

https://doi.org/10.1080/13676261.2014.901494

Ministry of Education Malaysia. (2015). MOOC: Massive Open Online Course. Putrajaya: MOE. Al Dafaei, M. I., Ismail, Z., Samsudin, M., \& Shakir, J. F. (2013). The mediating effect of selfefficacy towards the relationship between attitudes and level of use towards instructional computer technology in Oman. International Journal of Asian Social Science, 3(12), 2382-2398.

Pauli, K. P., Gilson, R. L., \& May, D. R. (2007). Anxiety and avoidance : The mediating effects of computer. Review of Business Information Systems, 11(1), 57-64. Retrieved from 
https://webcache.googleusercontent.com/search?q=cache:odJRanxE6YcJ:https://ww w.cluteinstitute.com/ojs/index.php/RBIS/article/download/4431/4519+\&cd=27\&hl=es $\& c t=c \mid n k \& g l=e c$

Pilli, O., \& Admiraal, W. (2017). Students' Learning Outcomes in Massive Open Online Courses (MOOCs): Some Suggestions for Course Design. Journal of Higher Education/Yüksekögretim Dergisi, 7(1), 46-71. https://doi.org/10.2399/yod.17.001

Rodriguez, B. P., \& Armellini, A. (2017). Developing self-efficacy through a massive open online course on study skills. Open Praxis, 9(3), 335-343. http://dx.doi.org/10.5944/openpraxis.9.3.659

Sailin, S. N., \& Mahmor, N. A. (2018). Improving student teachers' digital pedagogy through meaningful learning activities. Malaysian Journal of Learning and Instruction, 15(2), 143-173.

Sekaran, U., \& Bougie, R. (2016). Research methods for business: A skill-building approach. New Delhi: John Wiley \& Sons.

Wang, Y., \& Baker, R. (2015). Content or platform: Why do students complete MOOCs. MERLOT Journal of Online Learning and Teaching, 11(1), 17-30.

Zimmerman, B. J. (2000). Self-efficacy: An essential motive to learn. Contemporary Educational Psychology, 25(1), 82-91. https://doi.org/10.1006/ceps.1999.1016 